\title{
HIV-1-Related Central Nervous System Disease: Current Issues in Pathogenesis, Diagnosis, and Treatment
}

\author{
Serena Spudich ${ }^{1}$ and Francisco González-Scarano ${ }^{2}$ \\ ${ }^{1}$ Department of Neurology, Yale University School of Medicine, New Haven, Connecticut 06520 \\ ${ }^{2}$ Department of Neurology, The University of Texas School of Medicine at San Antonio, \\ San Antonio, Texas 78229 \\ Correspondence: scarano@mail.med.upenn.edu
}

\begin{abstract}
HIV-associated central nervous system (CNS) injury continues to be clinically significant in the modern era of HIV infection and therapy. A substantial proportion of patients with suppressed HIV infection on optimal antiretroviral therapy have impaired performance on neuropsychological testing, suggesting persistence of neurological abnormalities despite treatment and projected long-term survival. In the underresourced setting, limited accessibility to antiretroviral medications means that CNS complications of later-stage HIV infection continue to be a major concern. This article reviews key recent advances in our understanding of the neuropathogenesis of HIV, focusing on basic and clinical studies that reveal viral and host features associated with viral neuroinvasion, persistence, and immunopathogenesis in the CNS, as well as issues related to monitoring and treatment of HIV-associated CNS injury in the current era.
\end{abstract}

$\mathrm{H}_{\mathrm{a}}^{\mathrm{I}}$ V-1 infects the nervous system in virtually all patients with systemic infection and frequently causes central nervous system (CNS) and peripheral nervous system (PNS) disorders. Until the introduction of combination antiretroviral therapy (cART) in the mid-1990s, HIV-1-associated dementia (HAD) and related cognitive and motor disorders affected 20\%$30 \%$ of patients with advanced immunosuppression or AIDS. The incidence of overt HAD in countries where effective combination antiretroviral medications are widely available is now markedly diminished. However, in the setting of chronic, apparently systemically suppressive treatment, there appears to be a continued prevalence of mild-moderate neurocognitive impairment in a significant proportion or even a majority of patients. This disquieting finding, combined with the staggering numbers of patients who continue to be newly infected with HIV worldwide, and the limited availability of optimal antiretroviral treatment in many of the persons affected with this condition, make understanding and effectively preventing HIV-1-related neurological injury a continued key area of investigation. To encompass this more complex range of disorders seen in patients treated with cART, most

Editors: Frederic D. Bushman, Gary J. Nabel, and Ronald Swanstrom

Additional Perspectives on HIV available at www.perspectivesinmedicine.org

Copyright (C) 2012 Cold Spring Harbor Laboratory Press; all rights reserved; doi: 10.1101/cshperspect.a007120

Cite this article as Cold Spring Harb Perspect Med 2012;2:a007120 
investigators now refer to HIV-associated neurocognitive disorders (HAND) rather than $\mathrm{HAD}$ as the principal primary CNS complication of HIV infection.

\section{HISTORY}

A dementing illness characterized by attention and memory deficits, motor impairment, and personality changes was recognized in a significant proportion of patients with advanced AIDS within the first years of the HIV epidemic (Navia et al. 1986b). Further investigation of this disorder revealed that these complications were a direct result of HIV-1 infection and attendant inflammation in the CNS. The neuropathology was characterized by diffuse brain atrophy with large ventricles, widespread low-grade inflammation with microglial nodules, perivascular lymphocyte cuffing, multinucleated cells expressing HIV p24 and other antigens, and patchy demyelination and white matter gliosis (Gabuzda et al. 1986; Navia et al. 1986a). Although inexorably progressive to severe disability and death in the absence of disease-modifying HIV therapy, the course of this clinical disorder has been altered considerably by treatment with antiretroviral therapy and especially cART. Originally defined as the AIDS-dementia complex (ADC) based on motor, cognitive, and behavioral symptoms and signs, current research nosology defines a broader spectrum now called "HIV-associated neurocognitive disorder," with graded classifications based on abnormal performance on neuropsychological testing, and the presence or absence of a patient's perception of functional limitation related to cognitive impairment (Antinori et al. 2007). Changes in the severity of neurological disease in the current era may also be accompanied by alterations in the underlying etiology of neurological morbidity in the setting of long-term survival with HIV, including the consequences of possible ongoing low-grade viral replication and inflammation within the CNS, cumulative exposure to antiretroviral and other medications, chronic systemic inflammation leading to accelerated vascular disease, and the effects of comorbidities and neurodegeneration that occur with aging. Additionally, because cART appears to be beneficial in the amelioration and prevention of the most severe forms of HAND, newfound attention has been focused on the possible long-term cognitive benefits of initiation of cART in early stages of HIV infection.

\section{KEY ADVANCES IN THE AREA}

\section{Viral Entry and Maintenance of Infection in the Nervous System}

As with some other viruses that circulate in the bloodstream, HIV entry into the CNS is largely mediated through blood lymphocytes and monocytes that enter the perivascular spaces either in the course of their natural surveillance, or because they are attracted by chemokines to sites of inflammation. Viral strains isolated from the brain are more commonly CCR5tropic and replicate effectively in cultured macrophages, suggesting that monocytes may predominate as "Trojan horses" in the process of CNS entry, as described years ago for classically described lentiviruses such as visna virus of sheep (Haase 1986). Alternatively, HIV may be brought into the CNS by lymphocytes, which can harbor viruses that replicate in macrophages (Collman et al. 1992), or conceivably as free virions, where the means of entry would be through endothelial cells. Regardless of the mechanism of entry, cells of the macrophage lineage are the only cells in the brain that are routinely found to harbor HIV antigens or RNA by conventional methods such as immunohistochemistry or in situ hybridization for viral RNA, although other cell types such as astrocytes may harbor HIV sequences without robust expression of RNA (or proteins) (Wiley et al. 1986). Detection of such infection requires other methodology such as in situ polymerase chain reaction (PCR) amplification or laser capture microdissection followed by PCR (Churchill et al. 2009). Recent studies have also concentrated on determining whether a subset of monocytes is particularly important in either delivering virus to the CNS or in 
amplifying a local inflammatory process, whether such a subset is increased or enhanced by systemic inflammation mediated by circulating bacterial products, and which cytokines and chemokines increase the recruitment of monocytes and lymphocytes into the CNS and by extension are more likely to deliver virus into the brain (Fig. 1).

Although there is general agreement that the predominant infected cells are macrophagelike, there is controversy regarding which of the several subtypes of CNS macrophages are harboring HIV (macrophage subtypes are reviewed by Perry et al. 2010). Most investigators agree that perivascular macrophages, which are mostly derived from the circulating monocytes, are highly infected in the brains of HIVinfected persons or in macaques (rhesus or pig-tailed) that are infected experimentally with SIV (Kim et al. 2006); these may be labeled by CD163, a marker for this subtype that also appears to be increased in circulating monocytes in macaques with CNS infection (Borda et al. 2008). The life span of these perivascular macrophages was previously thought to be days or weeks; recent studies in rhesus macaques have indicated that they are probably longer-lived (Soulas et al. 2009). Multinucleated giant and other CNS lesions containing SIV in an experimental model or HIV in

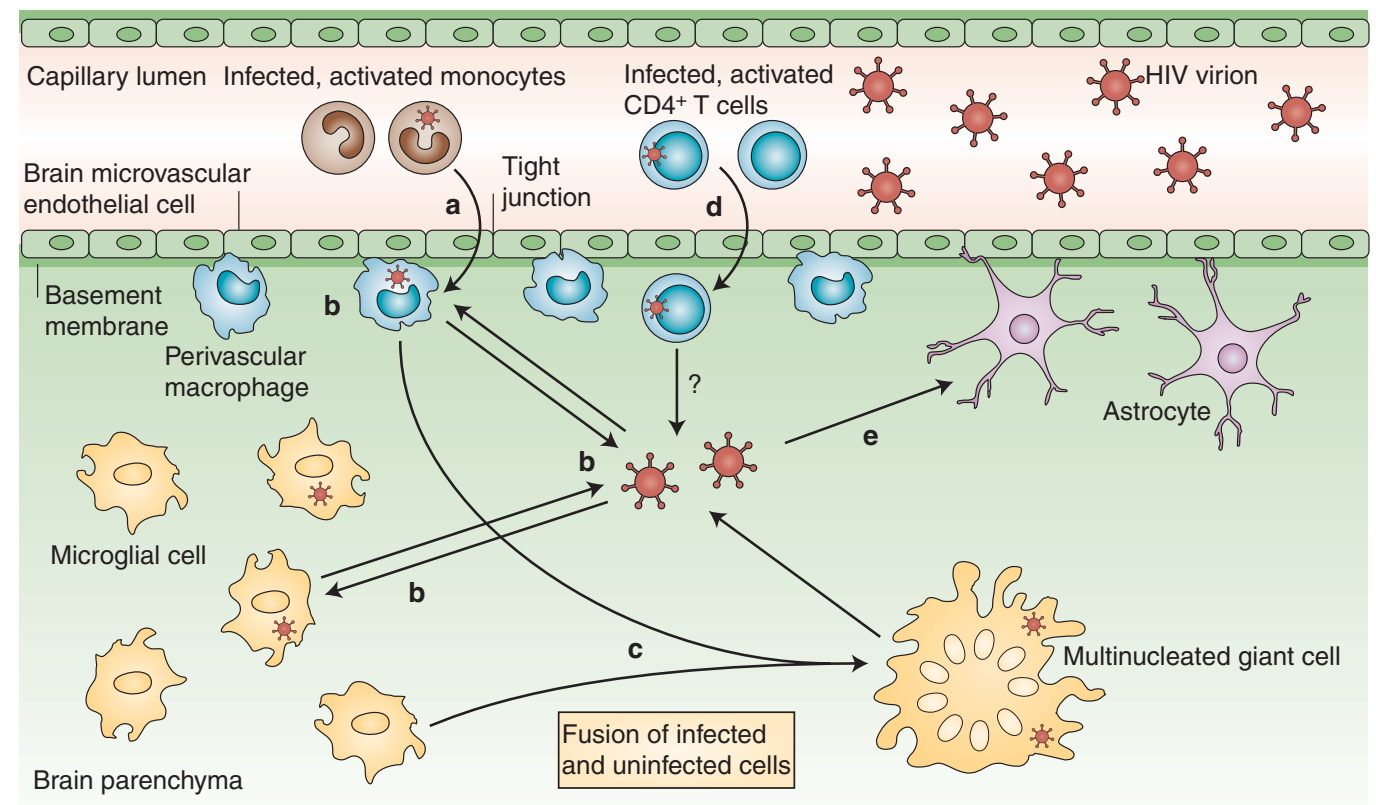

Figure 1. Potential models for HIV neuroinvasion and infection of the central nervous system (CNS). (a) HIV-infected monocytes with an activated phenotype may transport HIV into the nervous system via migration across the blood-brain barrier. (b) Infected monocytes likely differentiate into perivascular tissue macrophages and proceed to produce HIV within the CNS. This macrophage infection and replication allows for release of free virions and may facilitate infection of microglial cells. (c) Cell-to-cell fusion involving cells that express CD4 and HIV coreceptors results in formation of multinucleated giant cells within the brain, a hallmark of HIV-related brain pathology. (d) Infected CD $4^{+}$T lymphocytes may also serve as a mechanism of entry of HIV into the brain. There is varied evidence regarding the relative contribution of CD4 ${ }^{+} \mathrm{T}$ lymphocytes versus cells of the monocyte/macrophage in initiating and sustaining HIV infection within the CNS. (e) Although astrocytes might harbor HIV and also contribute to HIV-related brain disease through mechanisms of astrogliosis induced by local chemokines and cytokines, astrocytes infection is not thought to support ongoing replication within the CNS. (Adapted from Gonzalez-Scarano et al. 2005; with permission, from Macmillan Publishers Ltd. (C) 2005.) 
autopsy samples are composed of cells expressing different macrophage markers, including CD163, CD68, and CD387; some cells appear productively infected; others do not express viral antigens (Soulas et al. 2011). Nevertheless, although it has previously been suggested that because of their rapid turnover perivascular macrophages could not contribute to the longterm presence of HIV/SIV within the CNS, which could then serve as a reservoir when systemic infection was cured, these more recent discoveries would propose that indeed this perivascular population could harbor virus for long periods of time. Parenthetically, the astrocytes found to be infected using sensitive methodologies are often close to the perivascular spaces.

Microglia, which are parenchymal, or deeper within the brain, are known to be longlived and are replaced only infrequently during an individual's lifetime. Recent studies in mice have indicated that they may represent a separate ontogeny within bone marrow cells (Ginhoux et al. 2010), although hematopoietic circulating cells could potentially also give rise to morphologically appearing microglial cells, albeit a small minority. However, there is some controversy as to whether true microglia are commonly infected by HIV, and some investigators believe that they are never infected. Multinucleated giant cells, the pathological hallmark of HIV in the CNS, arise from macrophage-type cells, and although their frequent perivascular location would suggest they are from that perivascular macrophage population, there are no markers that can reliably confirm this. Furthermore, the life span of multinucleated giant cells is completely unknown, although one can speculate based on their presence in pathological specimens that they last at least days.

Studies performed well over a decade ago first proposed that a subset of monocytes, characterized by expression of the markers CD14 and CD69, were particularly prominent in patients with HIV neurological complications and specifically HAD (Pulliam et al. 1997). More recently, investigators from the same group related these original findings to a less impressive but still measurable increase in $\mathrm{CD} 14 / \mathrm{CD} 69$ positive cells in patients on cART with dementia in comparison to those without (Kusdra et al. 2002). Similarly, in the rhesus macaque model of SIV encephalitis (SIVE) increased monocyte turnover and expression of the CD163 marker are associated with brain penetration and encephalitic changes (Burdo et al. 2010).

While these observations were developing, independent evidence that systemic inflammation driven by depletion in the gut immunological system and consequent microbial translocation had a role in HIV pathogenesis arose from several areas, including animal models and human observations (see Lackner et al. 2011 for details). This led to a series of discoveries suggesting that microbial translocation and concomitant immunological activation are associated with the presence of neurological complications in HIV infections (Ancuta et al. 2008). Furthermore, this finding may explain why there has been a strong correlation between inflammatory activity, as characterized by the presence of macrophages expressing activation markers in the CNS, and the development of HAND or HAD. This correlation may be as strong as that of the presence of viral proteins and other evidence of HIV replication.

A model that incorporates current concepts of systemic pathogenesis and the CNS-specific observations would then propose that infection of the CNS is driven by systemic activation of monocytes - at least partly owing to microbial translocation from a depleted gut immune system-which then are more likely to invade the brain perivascular space. As some of these cells are infected, they bring in virus that spreads locally and sets up a nidus of replication independent from the systemic circulation (see next section).

Concomitantly, the perivascular inflammation results in the secretion of cytokines and chemokines that in turn amplify the reaction, attracting in addition other circulating monocytes and infected $\mathrm{CD} 4^{+} \mathrm{T}$ lymphocytes that can also add to the CNS viral burden (Xing et al. 2009). Chief among the chemokines associated with HIV infection of the CNS is MCP1 (CCL2), which is present in easily measurable 
concentrations in the cerebrospinal fluid (CSF) and is associated with dementia, but also IP10 and others (see next sections).

\section{CNS Compartmentalization}

Studies in acute HIV infection have shown that virus is present in the CSF at early points during HIV infection, including in some patients with primary infection (Schnell et al. 2010); whether such an early seeding forms the basis for independent replication in the brain, or whether it is cleared and virus penetrates at other points in the course of the infection, has been the subject of many excellent studies without a clear consensus (Caragounis et al. 2008; Harrington et al. 2009). It is likely that different scenarios take place depending on the host, the route of infection, and possibly the individual isolates. Nevertheless, although the details may vary, long-term HIV infection leads to genetically isolated populations in the CNS, as evidenced by studies using pol, env, nef, and other genes (Thomas et al. 2007; Brown et al. 2011; Cowley et al. 2011; Gray et al. 2011). The most recent studies (Brown et al. 2011) have used single genome analysis (SGA) to overcome potential PCR artifacts and confirmed the conclusions derived with bulk amplification before the development of SGA. Additionally, studies in experimental infection of rhesus macaques with a cloned SIV isolate suggested that virus is not only compartmentalized in the CNS, but that different regions have potentially different env genotypes, setting the stage for independent entry events, some potentially early in the course of infection, some perhaps much later (Chen et al. 2006; Reeve et al. 2010).

Important yet still unresolved questions are whether the genetic compartmentalization observed in the CNS is the result of a founder effect with concomitant independent divergence, or whether there are specific selective pressures that promote selection, and what those selective pressures might be. Most likely the end result observed in cross-sectional analyses such as the ones cited previously are attributable to a combination of factors. There have been comparatively few studies designed to differentiate between genetic divergence owing to a founder effect and adaptive evolution; even fewer have estimated the timing of divergence in the CNS. Most investigators who have compared the rate of nonsynonymous to synonymous changes have concluded that evolution in pol, env, or nef in brain isolates is adaptive (Huang et al. 2002; Thomas et al. 2007b; Gray et al. 2011). What is less clear is which specific pressures are driving the adaptation. Theoretically, enhanced replication in macrophageselaborated below-response to antiretrovirals, or the peculiarities of the immune response within the CNS could be playing a role.

Chief among the potential selective pressures are the requirement for robust replication in macrophages. Macrophages express CD4 at lower levels than $\mathrm{CD}^{+}{ }^{+}$lymphocytes (Lee et al. 1999). Accordingly, HIV isolates from the CNS tend to have an increased capacity to use reduced levels of CD4 for entry and infection (Peters et al. 2004; Martín-Garcia et al. 2006; Thomas et al. 2007a); however, many of these isolates have been obtained postmortem, and could reflect an end-stage phenotype. Similarly, the CNS is an environment with a relatively low penetration of antibodies, and configurations that might promote neutralization are better "tolerated" under these circumstances of "immunological privilege." In fact, isolates from the brain have been shown to be sensitive to neutralizing sera, and particularly to a monoclonal antibody (b12) that overlaps the CD4 binding site (van Marle et al. 2002; MartínGarcia et al 2005; Dunfee et al. 2007).

Antiretroviral use and its penetration into the CNS is another potential selective mechanism for HIV strains in this regard, and a few studies have shown discordance between the resistance phenotypes in the blood and CSF-derived strains (Haas 2004; Smit et al. 2004). However, the turnover of virus-infected cells can be different between the plasma and CSF compartments (Schnell et al. 2009) consistent with the predominantly infected cell type in each compartment-lymphocytes in the circulation, longer-lived macrophages in the CNS - and discordance in the sensitivity to antiretrovirals may be attributable to viral 
genetic information being obtained as a "snapshot" rather than representing a true biological phenomenon (Haas 2004). For example, resistance genotypes detected in the circulation at one point may potentially not appear in the CSF until later because of slower replication cycles.

\section{Mechanisms of CNS Injury}

The pathophysiology of HAD and HAND must eventually involve neurons, the principal effector cells of the nervous system. To understand the apparent paradox of cognitive and motor symptoms in what is principally a macrophage and microglial infection, investigators have developed a number of in vitro and in vivo models, many using combinations of infected monocyte-derived macrophages with mammalian (often rat, but also human) neurons. A somewhat simplistic summary of the vast literature on this subject divides the putative neurotoxic molecules into those that are the direct result of virus in the extracellular fluid, and those that propose that neurotoxicity is the end result of macrophage and microglial reaction to a chronic infection with HIV.

Among the viral proteins that have been implicated in neurotoxicity are gp120, Tat, Vpu, and Vpr. Of these, gp120 and Tat have received the widest attention, and unquestionably they can cause neurotoxicity in vitro. More complicated is the question of whether the concentrations of proteins that can be achieved in the in vivo extracellular fluid ever approach the concentrations required to affect neurons. For gp120, this may be the case, but extracellular concentrations of Tat in the nanogram range are difficult to visualize.

A second pathway of neurotoxicity involves the production of potentially neurotoxic factors in association with macrophage infection. Among the factors implicated in neurotoxicity are quinolinic acid, tumor necrosis factor, platelet activating factor, and arachidonic acid metabolites. Some of these have been detected in the CSF, and related to neurocognitive functioning, whereas others have been primarily tested in vitro. Many investigators have proposed that a common end pathway of toxicity is through excitation of $N$-methyl-D-aspartate (NMDA)-subtype glutamate receptors, which has the potential for mediating apoptosis. Evidence supporting this model includes experiments that show that decreasing glutamate secretion by infected macrophages is partially protective in an in vitro model of macrophage-mediated neurotoxicity (O'Donnell et al. 2006), that toxicity associated with viral proteins is dependent on expression of these receptors, and that the areas that are most affected are associated with a concentration of NMDA receptors.

An intriguing recent finding, seemingly unrelated to HIV, comes from the work of ShauKwaun Chen and colleagues. They described a mouse mutant in the Hoxb8 gene that has a phenotype of excessive grooming (Chen et al. 2010). However, in the relevant CNS regions, this gene is normally expressed in microglia only, and the phenotype could be rescued by bone marrow transplantation. This article raises the possibility that microglia can affect complex behaviors even in the absence of neurodegeneration, although it is still quite possible that the effects are attributable to aberrant secretion of cytokines. As such, it opens the door for a mechanism of HIV effect, potentially reversible, that does not depend on the classic findings of neuronal dropout, and could occur without such histopathological changes.

\section{Strain-Specific Neuropathogenesis}

A number of studies have related specific HIV sequences, primarily in gp 120 , to the development of HAND. Among these, those that associated either tropism in macrophages/microglia with specific genotypes are the most worthy of note. For example, position 306 influenced $\mathrm{M}$ tropism and CCR5 binding in a subset of brain-derived isolates (Dunfee et al. 2007). Similarly, a variant at position 283 (N283) was associated with brain infection and also had enhanced tropism for macrophages. These collective findings suggest that changes that enhance $M$ tropism are associated with brain infection, but also that specific mutations are often 
context-dependent and that a universal brain signature is unlikely.

Similarly, in view of the considerable burden of HIV infection in Africa as well as other developing countries, many investigators have examined the prevalence of neurological disorders in individuals who are infected with HIV clades other than the clade B that is predominant in the developed world. Those studies are difficult, because neurological and psychiatric care is suboptimal in developing countries, and because most if not all of the more sophisticated instruments that are used to determine CNS involvement depend on cultural context. Nevertheless, it is clear that HIV strains from clades other than B are associated with HAND. For example, Mahadevan et al. (2007) studied the brains of patients with clade $\mathrm{C}$ infection and found evidence of p24 antigen expression in macrophage-like cells in patients who had opportunistic infections such as toxoplasmosis. The pattern was similar to that of clade B CNS infiltration, but there were no multinucleated giant cells. In addition, Sacktor and coworkers in Uganda (Sacktor et al. 2009) showed that dementia occurs in patients with clade D infection, possibly in greater proportion than in patients with clade $\mathrm{A}$ infection in the same region.

\section{Biomarkers of CNS Disease}

As the brain and spinal cord are relatively inaccessible for assessment, surrogate biomarkers of CNS disease may provide some insight into ongoing processes relevant to HIV infection. However, a major problem has been identifying markers that are specific enough and also measurable with assays routinely available.

Measurement of HIV RNA in the CSF is the most practical means of assessing CNS "viral load." CSF HIV RNA is ubiquitous during chronic untreated HIV infection, with levels that trend as the levels in blood but typically are 10-fold lower in absolute terms (Spudich et al. 2005; Marra et al. 2007). In untreated patients, HIV RNA levels may be higher in patients with active neurological disease as compared with asymptomatic individuals (Brew et al.
1997; Robertson et al. 1998). However, the CSF HIV RNA may arise from sources other than the CNS, and in addition to the brain, may also reflect virus in the systemic circulation that has been transported or "leaked" to the nervous system. Importantly, genetic compartmentalization of virus and detection of divergent viral quasispecies between these tissues indicates that CSF HIV is not entirely a spillover from that present in blood (see previous sections for references).

With the recognition that markers of cellular activation and inflammation were useful indicators of disease activity in systemic HIV infection, attention turned to the utility of following such measures in the CNS compartment. Soluble CSF markers of macrophage activation (neopterin), chemokines stimulating ingress of macrophages and lymphocytes across the blood-brain barrier (CCL2/MCP1 and CXCL10/IP10), and molecules involved at various stages in the pathways for cell turnover and activation within the nervous system compartment are used to monitor processes that are thought to serve as the substrate for neuropathology in HAND (for review, see Cinque et al. 2007). In one small study, moderately elevated CSF neopterin predicted subsequent progression to HAD (Brew et al. 1996). However, although such markers have been correlated to disease activity, they have not been clinically used for diagnosis or monitoring of NeuroAIDS owing to lack of specificity for active neurological disease in the setting of the immune activation characterizing HIV infection (Gisslén et al. 2009). Recently, attention has turned to plasma markers related to immunopathogenesis of systemic HIV, including soluble CD14 and lipopolysaccharide (Ancuta et al. 2008; Sun et al. 2010). Direct markers of neurological injury assayed in CSF, including neurofilament light chain protein (NFL), tau protein, and precursors and products of amyloid protein (amyloid precursor proteins and A $\beta 1-42$ ) may be more valuable as measures of active neurodegeneration or injury (Hagberg et al. 2000; Gisslen et al. 2007, 2009; Clifford et al. 2009).

Imaging of the brain has been extensively investigated and used; overt $\mathrm{HAD}$ may be 
characterized by cerebral atrophy with or without periventricular white matter hyperintensities, which are diffuse, largely symmetric, and not characterized by edema or mass effect (Price et al. 1991). However, these findings are neither specific for nor ubiquitous in HAD, especially in its earlier stages, and, conversely, brain atrophy is noted in many neuroasymptomatic HIV-infected patients. Magnetic resonance spectroscopy (MRS), which detects cellular and biochemical processes based on diffusion of molecules through cerebral tissues, has yielded more specific insight into the inflammatory and neuronal processes occurring in the nervous system throughout the course of HIV infection. Overt HAD is associated with reduced relative levels of $N$-acetylaspartate, indicating decreased neuronal function, and elevated levels of choline, associated with brain inflammation and membrane turnover (Meyerhoff et al. 1994; Chang 1995). Similar, although less severe, patterns are seen in asymptomatic, untreated HIV infection, indicating that MRS may be a valuable preclinical marker of active CNS disease (Meyerhoff et al. 1999). Although changes in cerebral metabolites may indicate regional inflammation and neuronal injury, more subtle and potentially more neuropathologically relevant information may be obtained by systematic evaluation of white matter tracts or white matter morphometry in the brain by diffusion tensor imaging (DTI). Some early work in this area suggests that in neuroasymptomatic HIV, there are reductions in major white matter tracts in a number of brain regions (Pomara et al. 2001; Thurnher et al. 2005; Chang et al. 2008). More global sophisticated brain morphometry measurement may be used to detect focal atrophy of gray or white matter structures (Wang et al. 2009). Functional magnetic resonance imaging ( $\mathrm{fMRI}$ ), which takes advantage of the fact that hemodynamics in the brain are closely linked to neural activity, uses techniques that measure cerebral blood flow and blood oxygen level dependence (BOLD) signals. Early studies in this area show reduced baseline cerebral blood flow and increased functional demand in the brain parenchyma in $\mathrm{HIV}$-infected patients
(Ances et al. 2008, 2010). Detection of abnormalities in neuroasymptomatic patients underscores the potential utility of functional MRI as assessment before development of overt neurological disease. Similar pathology of impaired blood flow may be detected by simpler cerebral perfusion imaging, which may additionally have a role in the assessment and monitoring of HIV-related CNS disease (Ances et al. 2009).

\section{Beneficial Effects of Antiretroviral Therapy in HIV-Associated CNS Disease}

Combination antiretroviral therapy has had a dramatic beneficial impact on the incidence and prevalence of severe forms of HAND or HAD. The Euro-SIDA cohort study clearly showed a decline in incidence of severe dementia (then termed AIDS-dementia complex, or $\mathrm{ADC})$, related to introduction of protease inhibitors and use of cART (d'Arminio Monforte et al. 2004). More recent evidence from the CHARTER study indicates a greatly reduced prevalence $(2 \%$ overall) of severe HAD in a cohort of HIV-infected individuals in the current era (recruited between 2003 and 2007) (Heaton et al. 2010). This improvement in the prevalence and incidence of severe HAND with cART reflects the generally beneficial effect of initiation of cART on neurocognitive performance witnessed in studies of initiation of antiretroviral therapy (Marra et al. 2003; Robertson et al. 2004; Cysique et al. 2006).

What are the biological underpinnings of this improvement? Blood and CSF viral burden are clearly reduced by cART (Marra et al. 2003; Spudich et al. 2005, 2006), and the initiation of cART is associated with sequential reduction in HIV RNA levels in both compartments over time (Ellis et al. 2000). CNS inflammation, the putative substrate of ongoing CNS injury in the setting of HIV, is also partly ameliorated by cART. Treatment is associated with reduced levels of markers of intrathecal inflammation, such as cellular markers of T-cell activation, CSF white blood cell (WBC), CSF neopterin, and $\beta-2$ microglobulin (Yilmaz et al. 2004; Spudich et al. 2006; Sinclair et al. 2008). Finally, markers of active neural injury in the CSF, 
including CSF NFL and tau protein are reduced in the setting of cART and have been observed to decay over time in subjects initiating therapy (Mellgren et al. 2007).

\section{Persistent Evidence of HAND despite Antiretroviral Therapy}

HAND is a clinical diagnosis, currently defined based on abnormal cognitive and motor performance on neuropsychological tests according to criteria that denote three levels of $\mathrm{HIV}$-associated neurological disease: asymptomatic neurocognitive impairment (ANI), mild neurocognitive disorder (MND), and HAD (Antinori et al. 2007, see Table 1). A number of recent studies have documented persistence of neurocognitive abnormalities, predominantly along the milder spectrum of HAND, in the setting of CART, with a prevalence ranging between $18 \%$ and $52 \%$ in varied settings (Robertson et al. 2007; Heaton et al. 2010; Cysique and Brew 2011). Studies including subjects with comorbidities that potentially confound the diagnosis of HAND, including current or past substance abuse, mental health disorders, head trauma, low education level, and coinfection with hepatitis, find a higher prevalence (up to $83 \%$ HAND in the highest "comorbidity" group in CHARTER), whereas those excluding subjects with significant relevant comorbidities and with low CD4 nadirs had lower, but not negligible, frequency of impairment (Table 1) (Heaton et al. 2010).

The dramatic change in the severity and perhaps phenotype of the clinical disorders associated with HIV suggests that the etiology of Neuro-AIDS may have altered during this time. A small number of studies have focused on brain pathology in the era since the introduction of cART. Examination of 589 brains obtained mainly from subjects on antiretroviral therapy available through the National NeuroAIDS Tissue Consortium (NNTC) revealed a significant reduction in the proportion of subjects with typical HIV-related brain pathology (including encephalitis, microglial nodules, and leukoencephalopathy) compared with the pre-antiretroviral era (Everall et al. 2009; Heaton et al. 2010). However, 78\% overall had neuropathological abnormalities including vascular pathologies, Alzheimer type II gliosis, and other infectious and noninfectious pathologies. Premorbid HAND diagnosis (in 82\%) in this cohort did not correlate with HIV-related brain pathology.

Although classical HIV-related brain pathology may no longer be the only substrate for HAND, HIV-driven mechanisms may still be important CNS abnormalities in the setting of cART. Real-time PCR quantification of HIV RNA in autopsy specimens from the NNTC has revealed detectable HIV-1 RNA in brain in a majority of cART-treated subjects (Kumar

Table 1. Diagnostic research criteria for HAND

\begin{tabular}{lll}
\hline Diagnostic entity & \multicolumn{1}{c}{ Cognitive performance } & \multicolumn{1}{c}{ Functional status } \\
\hline $\begin{array}{l}\text { Normal } \\
\begin{array}{l}\text { Asymptomatic } \\
\text { neurocognitive } \\
\text { impairment (ANI) }\end{array}\end{array}$ & $\begin{array}{l}\text { Normal } \\
\text { Acquired impairment in at least two } \\
\text { cognitive domains }(<1 \mathrm{SD})\end{array}$ & $\begin{array}{l}\text { Normal } \\
\text { No perceived impact on daily function }\end{array}$ \\
$\begin{array}{l}\text { disorder (MND) } \\
\text { HIV-associated dementia } \\
\text { (HAD) }\end{array}$ & $\begin{array}{c}\text { Acquired impairment in at least two } \\
\text { cognitive domains }(<1 \mathrm{SD})\end{array}$ & $\begin{array}{c}\text { Perceived interference with daily } \\
\text { function to at least a mild degree } \\
\text { (work inefficiency, reduced mental } \\
\text { acuity) }\end{array}$ \\
& $\begin{array}{l}\text { domains, typically in multiple domains } \\
\text { with at least two domains with severe } \\
\text { impairment }(<2 \text { SD) }\end{array}$ & $\begin{array}{c}\text { Marked impact on daily function } \\
\end{array}$ \\
\hline
\end{tabular}

Adapted from Antinori et al. 2007; with permission, from Wolters Kluwer Health (C) 2007. 
et al. 2007), and abnormal levels of microglial activation in the CNS were found to persist in neuroasymptomatic subjects with successful plasma viral suppression on cART in another recent neuropathological study (Anthony 2005). These studies are corroborated by evidence that intrathecal inflammation as detected in CSF persists in the setting of long-term, systemically effective cART (Eden et al. 2007; Yilmaz et al. 2008). Although even in the setting of therapy that fails to successfully suppress plasma HIV RNA (Spudich et al. 2006), cART usually successfully suppresses CSF HIV RNA below detectable levels, viral "escape" in the CSF may occur in up to $10 \%$ of individuals on current regimens (Eden et al. 2010), and in rare cases dramatic CSF "escape" has been associated with clinically progressive neurological disease (Canestri et al. 2010).

\section{CNS Penetration of cART}

The CNS is separated from the systemic circulation by blood-brain and blood-CSF barriers, thus potentially allowing for a "sanctuary" of infection that is only partially reached by some antiretroviral medications which, owing to molecular size or hydrophilicity, do not readily cross the blood-brain barrier. Based on structural composition and effect on CSF HIV RNA, antiretrovirals have been ranked according to their estimated CNS penetration effectiveness (CPE), with a combination of drugs in a regimen assigned a combined "CPE" score based on the sum of their individual rankings (Table 2) (Letendre et al. 2008). Given that treatment with cART benefits the nervous system in terms of both the detection and magnitude of HIV infection and attendant inflammation within the CNS, more potent activity of antiretroviral medications within the CNS might provide additional benefit in the setting of treatment of HAND. Despite predominant concurrence between numerous studies that regimens with higher CPE scores tend to lead to more successful suppression of HIV RNA levels in the CNS (Letendre et al. 2008; Marra et al. 2009), the evidence that enhanced CPE scores are related to improved neurocognitive outcomes in subjects with HIV infection is less definitive. Whereas some observational studies show a cognitive benefit of initiation of regimens with higher CPE scores in the setting of HIV-related CNS disease (Letendre et al. 2004; Tozzi et al. 2009), others show poorer neurocognitive performance in subjects treated with

Table 2. Antiretroviral central nervous system penetration effectiveness (CPE) scoring system used in recent clinical studies

\begin{tabular}{|c|c|c|c|}
\hline Increasing CNS penetration $\rightarrow$ & 0 & 0.5 & 1 \\
\hline Nucleoside reverse transcriptase inhibitors & $\begin{array}{l}\text { Didanosine } \\
\text { Tenofovir } \\
\text { Zalcitabine } \\
\text { Adefovir }\end{array}$ & $\begin{array}{l}\text { Emtricitabine } \\
\text { Lamivudine } \\
\text { Stavudine }\end{array}$ & $\begin{array}{l}\text { Abacavir } \\
\text { Zidovudine }\end{array}$ \\
\hline Nonnucleoside reverse transcriptase inhibitors & & Efavirenz & $\begin{array}{l}\text { Delavirdine } \\
\text { Nevirapine }\end{array}$ \\
\hline Protease inhibitors & $\begin{array}{l}\text { Nelfinavir } \\
\text { Ritonavir } \\
\text { Saquinavir } \\
\text { Saquinavir/r } \\
\text { Tipranavir/r }\end{array}$ & $\begin{array}{l}\text { Amprenavir } \\
\text { Atazanavir } \\
\text { Fosamprenavir } \\
\text { Indinavir }\end{array}$ & $\begin{array}{l}\text { Amprenavir/r } \\
\text { Atazanavir/r } \\
\text { Fosamprenavir/r } \\
\text { Indinavir/r } \\
\text { Lopinavir/r }\end{array}$ \\
\hline Entry inhibitors & $\begin{array}{l}\text { Enfuvirtide } \\
\text { T-1249 }\end{array}$ & & $\begin{array}{l}\text { Maraviroc } \\
\text { Vicriviroc }\end{array}$ \\
\hline Integrase inhibitors & & $\begin{array}{l}\text { Raltegravir } \\
\text { Elvitegravir }\end{array}$ & \\
\hline
\end{tabular}

Adapted from Smurzynski et al. 2011; with permission, from Wolters Kluwer Health (C) 2011. 


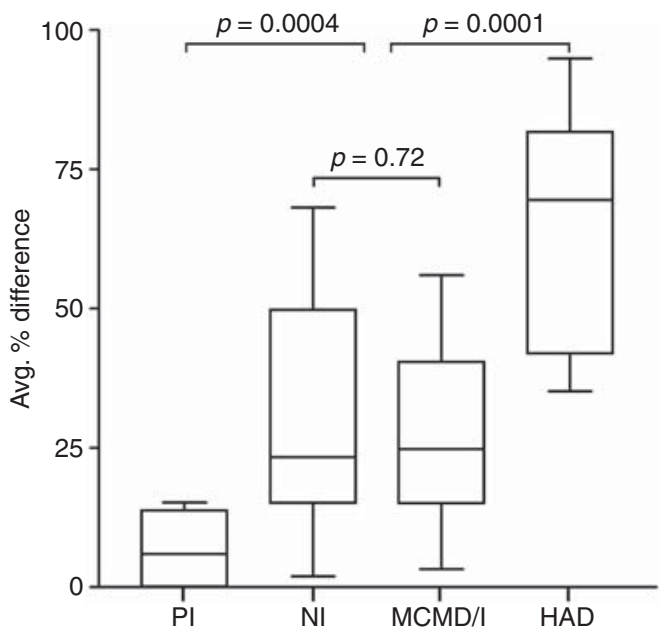

Figure 2. Heterduplex tracking assay (HTA) was used to compare V1/V2 and V4/V5 env populations in blood plasma (BP) and CSF from subjects with distinct stages of HIV infection and neurological status (PI, primary infection; NI, not impaired; $\mathrm{MCMD} / \mathrm{I}$, minor cognitive and motor disorder; HAD, HIV-associated dementia). The \% difference for BP/CSF HTA band patterns was determined for each patient and the data compiled. A higher percentage difference indicates more discordant BP/CSF viral genetic populations for the particular region of env analyzed. The mean of V1/V2 and V4/V5 percent difference results was determined for each patient to reflect global env compartmentalization between BP and CSF, and results were compiled for comparison between the different disease categories. $p$ values shown were determined by Wilcoxon rank-sum test. (Adapted from Harrington et al. 2009; with permission, from Wolters Kluwer Health (C) 2009.)

regimens with higher CPE scores (Marra et al. 2009). A variety of issues may lead to the discrepant results of such studies. High $\mathrm{CPE}$ regimens may be especially important in conditions of robust brain and meningeal infection with HIV, which typically occur in later stages of chronic infection, when targeted therapy to CNS tissues may be key for control of compartmentalized viral replication (Fig. 2). Furthermore, retrospective, observational studies may be biased; for example, subjects with more profound neurological deficits may be started on regimens with higher CNS penetration. Such deficits may not be entirely reversible and thus
Pathogenesis and Management of Neuro-AIDS

persist despite high CPE regimens. A recent study did find a modest neurocognitive benefit of higher CPE scores (although only between patients with more than three drugs in their regimens and higher or lower CPE scores) in the context of randomized assignment of antiretroviral regimens (Smurzynski et al. 2011); additional randomized studies are warranted to directly examine this issue.

\section{New Research Areas}

\section{The Relationship among Aging, New Comorbidities, and HAND}

In resource-rich regions where life expectancy after HIV diagnosis in a young adult is estimated to be approximately 12 years below that of a noninfected individual (Lohse et al. 2007), longer duration of survival with chronic HIV-1 infection may change the scope and etiology of disorders affecting the CNS. A great deal of recent attention has been paid to the question of whether aging and HIV-1 will have a synergistic effect on neurodegeneration within the brain, "accelerating" injury triggered earlier by neuropathological processes associated with HIV. Systemic immunologic changes noted in HIV infection are in part characterized by markers of immunosenesence, and chronic infection with HIV is associated with the earlier onset of cancers and vascular disorders seen in HIV-uninfected persons at more advanced age (Desai and Landay 2010). However, the evidence that aging and HIV have an enhanced combined deleterious effect in the brain is mixed. A large cohort study enrolling subjects with HIV and advanced age, the Hawaii aging cohort, found a higher prevalence of cognitive deficits in older HIV-infected patients, related to $\mathrm{CD} 4$ nadir, insulin resistance, and presence of Apo E alleles (Valcour et al. 2004), and a recent neuroimaging study found that HIV and aging caused independent reductions in cerebral blood flow (Ances et al. 2010). However, the Multicenter AIDS Cohort Study (MACS) found no difference between older $\mathrm{HIV}^{+}$individuals and older $\mathrm{HIV}^{-}$individuals in rate of change in performance on longitudinal testing, 
suggesting the absence of an acceleration of neurological disease with aging (Becker et al. 2009). Two additional recent studies using wellmatched HIV-uninfected comparison groups in analyses of age effects on neurocognitive performance showed no combined effects of HIV and age on cognitive function (Cysique et al. 2011; Valcour et al. 2011). Other conditions are emerging in the setting of long-term survival with chronic HIV infection that may influence the integrity of the CNS and alter the substrate for cognitive and neurological impairment in HIV. In particular, cardiovascular risk factors such as hyperlipidemia, hypertension, carotid intima-media thickness, and past history of cardiovascular disease have been identified recently as associated with reduced neurocognitive performance in HIVinfected subjects (Becker et al. 2009; Foley et al. 2010; Wright et al 2010). It is unclear whether these risk factors are non-HIV-related cofactors that influence cognitive outcomes, HIV- or cART-related systemic effects that parallel processes of CNS injury, or conditions that are directly involved in the mechanisms of HAND in the current era. Further efforts to investigate the association between vascular changes and clinical, pathological, and imaging changes in the setting of HIV are warranted to expand possible treatment approaches to HAND.

\section{Importance of Acute/Early Infection}

Although severe HAD clearly is a condition associated with long-term chronic HIV infection and immunosuppression, recent evidence that acute and early HIV are crucial for systemic disease pathogenesis has raised questions about whether early stages of HIV might also be important for neuropathogenesis. It has long been known that HIV may enter the nervous system within the first weeks after initial systemic infection (Schacker et al. 1996; Pilcher et al. 2001). It is now clear that acute infection also initiates a cascade of neuroinflammation, providing conditions for inflammation-mediated injury within the CNS. Analysis of CSF from 96 antiretroviral naïve subjects at a median less than three months after HIV transmission revealed elevations in CSF WBC counts, neopterin, and CXCL10 equal to those in subjects with chronic HIV infection (Fig. 3) (Spudich et al. 2011).

Furthermore, neuroimaging studies in recently HIV-infected humans reveal lower nacetylacetate in the frontal cortex during early infection, suggestive of neuronal dysfunction or injury during this early period (Lentz et al. 2009). Follow-up longitudinal studies in this group reveal dynamic patterns of cerebral metabolites over the first year of infection (Lentz et al. 2011). Given that early HIV infection is characterized by neuroinflammation and evolving metabolite changes within the CNS, it is possible that either antiretroviral or antiinflammatory treatment initiated during early stages of infection may ameliorate injury sustained in the CNS during the early years of infection before immune systemic immunosuppression. Finally, the fact that CSF compartmentalization of HIV species may begin within the first year of HIV infection in some individuals (Schnell et al. 2010) suggests that treatment and eradication efforts may need to consider the CNS as a potential independent site of replication and mutation, beginning in the early stages of HIV.

\section{CONCLUSIONS}

There has been substantial progress in the recognition and treatment of the most severe forms of CNS HIV infection, and although the mechanisms leading to neurological dysfunction are still under investigation, the central role of macrophages and microglia is well established. Less well understood are the less severe forms of CNS disease now seen in the developed countrieswhere the use of cART is common-and the role of virus, inflammation, and CNS penetrance of antiretrovirals are areas of potential new discoveries. Similarly, there has not been any successful "adjuvant" therapy: that is, one designed to treat the CNS specifically rather than the virus. Such adjuvant treatment may be important in preventing or ameliorating HAND in the setting of cART. 

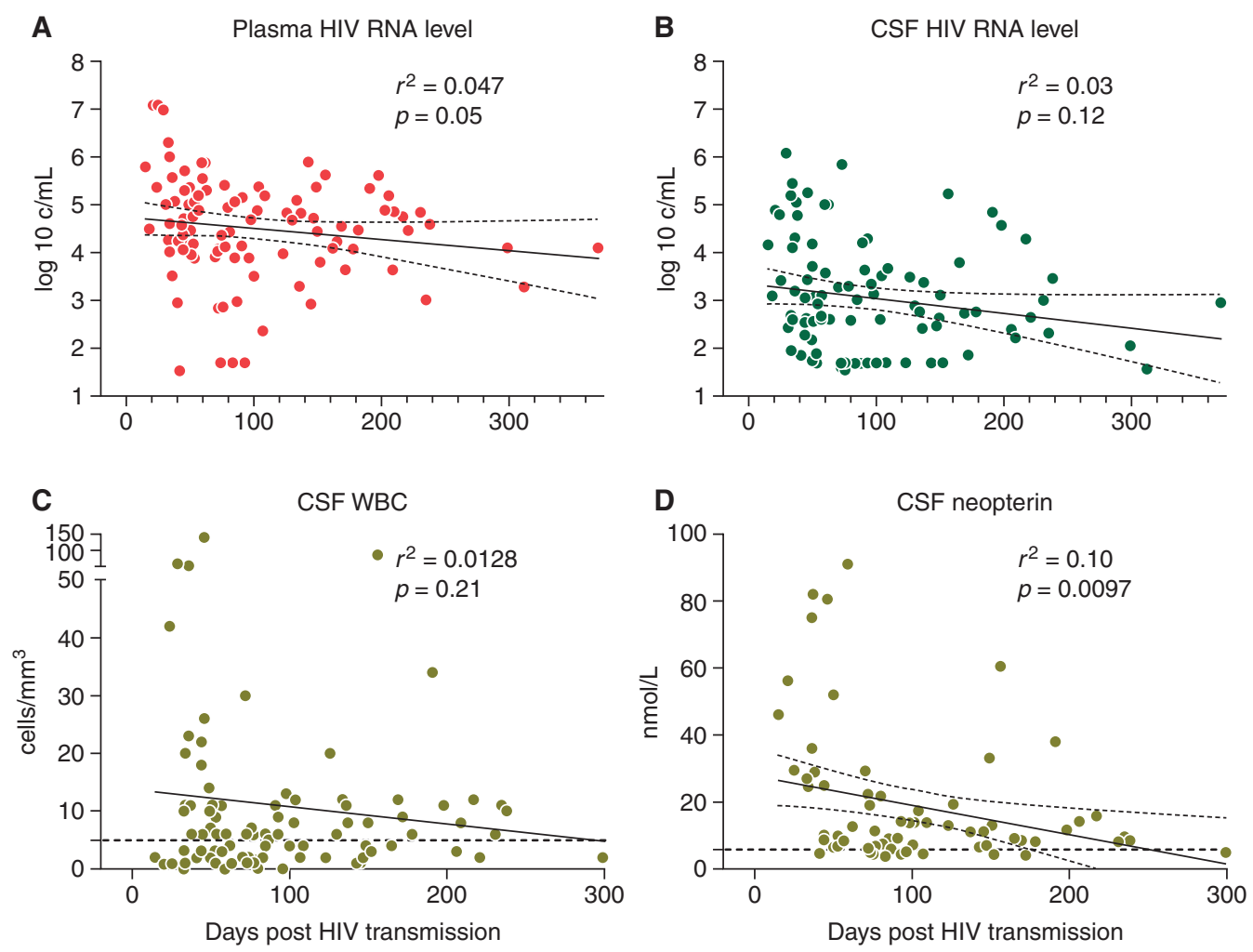

Figure 3. Baseline levels of markers of HIV infection and inflammation in a primary infection cohort are shown according to estimated days after transmission at blood and CSF sampling. Simple linear regression between the number of days post-estimated HIV transmission and $(A)$ blood plasma HIV RNA levels, $(B)$ CSF HIV RNA levels, $(C)$ CSF WBC counts, and (D) CSF neopterin levels. Regression lines (solid) and 95\% confidence intervals (dotted) are indicated; upper limit of normal values for CSF WBC and CSF neopterin are indicated on each graph by a dotted horizontal line. (Adapted from Spudich et al. 2011; with permission, from Oxford University Press (C) 2011.)

\section{ACKNOWLEDGMENTS}

We thank Dr. Anna Aldovini for her helpful review of this article. We also thank the National Institutes of Health for funding support (P50NS027405 and R01MH081772).

\section{REFERENCES}

${ }^{*}$ Reference is also in this collection.

Ancuta P, Kamat A, Kunstman KJ, Kim EY, Autissier P, Wurcel A, Zaman T, Stone D, Mefford M, Morgello S, et al. 2008. Microbial translocation is associated with increased monocyte activation and dementia in AIDS patients. PLoS One 3: e2516. doi: 10.1371/journal.pone.0002516.

Ances BM, Roc AC, Korczykowski M, Wolf RL, Kolson DL. 2008. Combination antiretroviral therapy modulates the blood oxygen level-dependent amplitude in human immunodeficiency virus-seropositive patients. J Neurovirol 14: 418-424.

Ances BM, Sisti D, Vaida F, Liang CL, Leontiev O, Perthen JE, Buxton RB, Benson D, Smith DM, Little SJ, et al. 2009. Resting cerebral blood flow: A potential biomarker of the effects of HIV in the brain. Neurology 73: 702-708.

Ances BM, Vaida F, Yeh MJ, Liang CL, Buxton RB, Letendre S, McCutchan JA, Ellis RJ.2010. HIV infection and aging independently affect brain function as measured by functional magnetic resonance imaging. J Infect Dis 201: 336-340.

Anthony IC, Ramage SN, Carnie FW, Simmonds P, Bell JE. 2005. Influence of HAART on HIV-related CNS disease and neuroinflammation. J Neuropathol Exp Neurol 64: 529-536.

Antinori A, Arendt G, Becker JT, Brew BJ, Byrd DA, Cherner M, Clifford DB, Cinque P, Epstein LG, Goodkin K, et al. 2007. Updated research nosology for HIV-associated neurocognitive disorders. Neurology 69: 1789-1799. 
Becker JT, Kingsley L, Mullen J, Cohen B, Martin E, Miller EN, Ragin A, Sacktor N, Selnes OA, Visscher BR. 2009. Vascular risk factors, HIV serostatus, and cognitive dysfunction in gay and bisexual men. Neurology 73: 1292-1299.

Borda JT, Alvarez X, Mohan M, Hasegawa A, Bernardino A, Jean S, Aye P, Lackner AA. 2008. CD163, a marker of perivascular macrophages, is up-regulated by microglia in simian immunodeficiency virus encephalitis after haptoglobin-hemoglobin complex stimulation and is suggestive of breakdown of the blood-brain barrier. Am J Pathol 172: 725-737.

Brew BJ, Dunbar N, Pemberton L, Kaldor J. 1996. Predictive markers of AIDS dementia complex: CD4 cell count and cerebrospinal fluid concentrations of $\beta$ 2-microglobulin and neopterin. J Infect Dis 174: 294-298.

Brew BJ, Pemberton L, Cunningham P, Law MG. 1997. Levels of human immunodeficiency virus type 1 RNA in cerebrospinal fluid correlate with AIDS dementia stage. J Infect Dis 175: 963-966.

Brown RJ, Peters PJ, Caron C, Gonzalez-Perez MP, Stones L, Ankghuambom C, Pondei K, McClure CP, Alemnji G, Taylor S, et al. 2011. Inter-compartment recombination of HIV-1 contributes to env intra-host diversity and modulates viral tropism and senstivity to entry inhibitors. J Virol 85: 6024-6037.

Burdo TH, Soulas C, Orzechowski K, Button J, Krishnan A, Sugimoto C, Alvarez X, Kuroda MJ, Williams KC. 2010. Increased monocyted turnover from bone marrow correlates with severity of SIV encephalitis and CD163 levels in plasma. PLoS Pathog 6: e1000842. doi: 10.1371/ journal.ppat.1000842.

Canestri A, Lescure FX, Jaureguiberry S, Moulignier A, Amiel C, Marcelin AG, Peytavin G, Tubiana R, Pialoux G, Katlama C. 2010. Discordance between cerebral spinal fluid and plasma HIV replication in patients with neurological symptoms who are receiving suppressive antiretroviral therapy. Clin Infect Dis 50: 773-778.

Caragounis EC, Gisslén M, Lindh M, Nordborg C, Westergren S, Hagberg L, Svennerholm B. 2008. Comparison of HIV-1 pol and env sequences of blood, CSF, brain and spleen isolates collected ante-mortem and postmortem. Acta Neurol Scand 117: 108-116.

Chang L. 1995. In vivo magnetic resonance spectroscopy in HIV and HIV-related brain diseases. Rev Neurosci 6: 365-378.

Chang L, Wong V, Nakama H, Watters M, Ramones D, Miller EN, Cloak C, Ernst T. 2008. Greater than age-related changes in brain diffusion of HIV patients after 1 year. J Neuroimmune Pharmacol 3: 265-274.

Chen MF, Westmoreland S, Ryzhova EV, Martín-García J, Soldan SS, Lackner A, González-Scarano F. 2006. Simian immunodeficiency virus envelope compartmentalizes in brain regions independent of neuropathology. J Neurovirol 12: 73-89.

Chen SK, Tvrdik P, Peden E, Cho S, Wu S, Spangrude G, Capecchi MR. 2010. Hematopoietic origin of pathological grooming in Hoxb8 mutant mice. Cell 141: 775-785.

Churchill MJ, Wesslingh SL, Cowley D, Pardo CA, McArthur JC, Brew BJ, Gorry PR. 2009. Extensive astrocyte infection is prominent in HIV-associated dementia. Ann Neurology 66: 253-258.
Cinque P, Brew BJ, Gisslen M, Hagberg L, Price RW. 2007. Cerebrospinal fluid markers in central nervous system HIV infection and AIDS dementia complex. Handb Clin Neurol 85: 261-300.

Clifford DB, Fagan AM, Holtzman DM, Morris JC, Teshome M, Shah AR, Kauwe JS. 2009. CSF biomarkers of Alzheimer disease in HIV-associated neurologic disease. Neurology 73: 1982-1987.

Collman R, Balliet JW, Gregory SA, Friedman H, Kolson DL, Nathanson N, Srinivasan A. 1992. An infectious molecular clone of an unusual macrophage-tropic and highly cytopathic strain of human immunodeficiency virus type 1. J Virol 66: 7517-7521.

Cowley D, Gray LR, Wesselingh SL, Gorry PR, Churchill MJ. 2011. Genetic and functional heterogeneity of CNSderived tat alleles from patients with HIV-associated dementia. J Neurovirol 17: 70-81.

Cysique LA, Brew BJ. 2011. Prevalence of non-confounded HIV-associated neurocognitive impairment in the context of plasma HIV RNA suppression. J Neurovirol 17: $176-183$.

Cysique LA, Maruff P, Brew BJ. 2006. Variable benefit in neuropsychological function in HIV-infected HAARTtreated patients. Neurology 66: 1447-1450.

Cysique LA, Maruff P, Bain MP, Wright E, Brew BJ. 2011. $\mathrm{HIV}$ and age do not substantially interact in HIV-associated neurocognitive impairment. J Neuropsych Clin $\mathrm{Neu}$ rosci 23: 83-89.

d'Arminio Monforte A, Cinque P, Mocroft A, Goebel FD, Antunes F, Katlama C, Justesen US, Vella S, Kirk O, Lundgren J. 2004. Changing incidence of central nervous system diseases in the EuroSIDA cohort. Ann Neurol 55: 320-328.

Desai S, Landay A. 2010. Early immune senescence in HIV disease. Curr HIV/AIDS Rep 7: 4-10.

Dunfee RL, Thomas ER, Wang J, Kunstman K, Wolinsky SM, Gabuzda D. 2007. Loss of the N-linked glycosylation site at position 386 in the HIV envelope V4 region enhances macrophage tropism and is associated with dementia. Virology 367: 222-234.

Dunfee RL, Thomas ER, Gabuzda D. 2009. Enhanced macrophage tropism of HIV in brain and lymphoid tissues is associated with sensitivity to the broadly neutralizing CD4 binding site antibody b12. Retrovirology 6: 69 .

Eden A, Price RW, Spudich S, Fuchs D, Hagberg L, Gisslen M. 2007. Immune activation of the central nervous system is still present after $>4$ years of effective highly active antiretroviral therapy. J Infect Dis 196: 1779-1783.

Eden A, Fuchs D, Hagberg L, Nilsson S, Spudich S, Svennerholm B, Price RW, Gisslen M. 2010. HIV-1 viral escape in cerebrospinal fluid of subjects on suppressive antiretroviral treatment. J Infect Dis 202: 1819-1825.

Ellis RJ, Gamst AC, Capparelli E, Spector SA, Hsia K, Wolfson T, Abramson I, Grant I, McCutchan JA. 2000. Cerebrospinal fluid HIV RNA originates from both local CNS and systemic sources. Neurology 54: 927-936.

Everall I, Vaida F, Khanlou N, Lazzaretto D, Achim C, Letendre S, Moore D, Ellis R, Cherne M, Gelman B, et al. 2009 Cliniconeuropathologic correlates of human immunodeficiency virus in the era of antiretroviral therapy. J Neurovirol 15: 1-11. 
Foley J, Ettenhofer M, Wright MJ, Siddiqi I, Choi M, Thames AD, Mason K, Castellon S, Hinkin CH. Neurocognitive functioning in HIV-1 infection: Effects of cerebrovascular risk factors and age. Clin Neuropsychol 24: 265-285.

Gabuzda DH, Ho DD, de la Monte SM, Hirsch MS, Rota TR, Sobel RA. 1986. Immunohistochemical identification of HTLV-III antigen in brains of patients with AIDS. Ann Neurol 20: 289-295.

Ginhoux F, Greter M, Leboeuf M, Nandi S, See P, Gokhan S, Mehler MF, Conway SJ, Ng LG, Stanley ER, Merad M, et al. 2010. Fate mapping reveals that adult microglia derive from primitive macrophages. Science 330: 841-845.

Gisslen M, Hagberg L, Brew BJ, Cinque P, Price RW, Rosengren L. 2007. Elevated cerebrospinal fluid neurofilament light protein concentrations predict the development of AIDS dementia complex. J Infect Dis 195: 1774-1778.

Gisslén M, Hagberg L, Cinque P, Brew B, Price R. 2008. CSF markers in the management of CNS HIV infection and the AIDS dementia complex. In The spectrum of neuroAIDS disorders: Pathophysiology, diagnosis, and treatment (ed. Goodkin K, Shapshak P, Vrma A), pp. 173-179. American Society for Microbiology, Washington, DC.

Gisslen M, Krut J, Andreasson U, Blennow K, Cinque P, Brew BJ, Spudich S, Hagberg L, Rosengren L, Price RW, et al. 2009. Amyloid and tau cerebrospinal fluid biomarkers in HIV infection. BMC Neurol 9: 63.

Gray LR, Gabuzda D, Cowley D, Ellett A, Chiavaroli L, Wesselingh SL, Churchill MJ, Gorry PR. 2011. CD4 and MHC class 1 down-modulation activities of nef alleles from brain- and lymphoid tissue-derived primary HIV-1 isolates. J Neurovirol 17: 82-91.

Gonzalez-Scarano F, Martin-Garcia J. 2005. The neuropathogenesis of AIDS. Nat Rev Immunol 5: 69-81.

Haas DW. 2004. Sequence heterogeneity and viral dynamics in cerebrospinal fluid and plasma during antiretroviral therapy. J Neurovirol 10 Suppl 1: 33-37.

Haase AT. 1986. Pathogenesis of lentivirus infections. Nature 322: $130-136$.

Hagberg L, Fuchs D, Rosengren L, Gisslen M. 2000. Intrathecal immune activation is associated with cerebrospinal fluid markers of neuronal destruction in AIDS patients. J Neuroimmunol 102: 51-55.

Harrington PR, Schnell G, Letendre SL, Ritola K, Robertson K, Hall C, Burch CL, Jabara CB, Moore DT, Ellis RJ, et al. 2009. Cross-sectional characterization of HIV-1 env compartmentalization in cerebrospinal fluid over the full disease course. AIDS 23: 907-915.

Heaton RK, Clifford DB, Franklin DR Jr, Woods SP, Ake C, Vaida F, Ellis RJ, Letendre SL, Marcotte TD, Atkinson JH, et al. 2010. HIV-associated neurocognitive disorders persist in the era of potent antiretroviral therapy: CHARTER study. Neurology 75: 2087-2096.

Huang KJ, Alter GM, Wooley DP. 2002. The reverse transcriptase sequence of human immunodeficiency virus type 1 is under positive evolutionary selection within the central nervous system. J Neurovirol 8: 281-94.

Hughes ES, Bell JE, Simmonds P. 1997. Investigation of the dynamics of the spread of HIV to brain and other tissues by evolutionary analysis of sequences from the p17gag and env genes. J Virol 71: 1272-1280.
Pathogenesis and Management of Neuro-AIDS

Kim W-K, Alvarez X, Fisher J, Bronfin B, Westmoreland W, McLaurin J, Williams K. 2006. CD163 identifies perivascular macrophages in normal and viral encephalitic brains and potential precursors to perivascular macrophages in blood. Am J Pathol 168: 822-834.

Kumar AM, Borodowsky I, Fernandez B, Gonzalez L, Kumar M. 2007. Human immunodeficiency virus type 1 RNA levels in different regions of human brain: Quantification using real-time reverse transcriptase-polymerase chain reaction. J Neurovirol 13: 210-224.

Kusdra L, McGuire D, Pulliam L. 2002. Changes in monocyte/macrophage neurotoxicity in the era of HAART: Implications for HIV-associated dementia. AIDS 16: $31-38$.

* Lackner AA, Lederman MM, Rodriguez B. 2011. HIV pathogenesis-The host. Cold Spring Harb Perspect Med doi: 10.1101/cshperspect.a007005.

Lee B, Sharron M, Montaner LJ, Weissman D, Doms RW. 1999. Quantification of CD4, CCR5, and CXCR4 levels on lymphocyte subsets, dendritic cells, and differentially conditioned monocyte-derived macrophages. Proc Natl Acad Sci 96: 5215-5220.

Lentz MR, Kim WK, Lee V, Bazner S, Halpern EF, Venna N, Williams K, Rosenberg ES, Gonzalez RG. 2009. Changes in MRS neuronal markers and $\mathrm{T}$ cell phenotypes observed during early HIV infection. Neurology 72: $1465-1472$.

Lentz MR, Kim WK, Kim H, Soulas C, Lee V, Venna N, Halpern EF, Rosenberg ES, Williams K, Gonzalez RG. 2011. Alterations in brain metabolism during the first year of HIV infection. J Neurovirol 17: 220-229

Letendre SL, McCutchan JA, Childers ME, Woods SP, Lazzaretto D, Heaton RK, Grant I, Ellis RJ. 2004. Enhancing antiretroviral therapy for human immunodeficiency virus cognitive disorders. Ann Neurol 56: 416-423.

Letendre S, Marquie-Beck J, Capparelli E, Best B, Clifford D, Collier AC, Gelman BB, McArthur JC, McCutchan JA, Morgello S, et al. 2008. Validation of the CNS penetration-effectiveness rank for quantifying antiretroviral penetration into the central nervous system. Arch Neurol 65: 65-70.

Lohse N, Hansen AB, Pedersen G, Kronborg G, Gerstoft J, Sorensen HT, Vaeth M, Obel N. 2007. Survival of persons with and without HIV infection in Denmark, 1995 2005. Ann Intern Med 146: 87-95.

Mahadevan A, Shankar SK, Parthasarathy S, Ranga U, Chickabasaviah YT, Santosh V, Vasanthapuram R, Pardo CA, Nath A, Zink MC. 2007. Characterization of HIV infected cells in infiltrates associated with CNS opportunistic infections in patients with HIV clade C infection. J Neuropathol Exp Neurol 66: 799-808.

Marra CM, Lockhart D, Zunt JR, Perrin M, Coombs RW, Collier AC. 2003. Changes in CSF and plasma HIV-1 RNA and cognition after starting potent antiretroviral therapy. Neurology 60: 1388-1390.

Marra CM, Maxwell CL, Collier AC, Robertson KR, Imrie A. 2007. Interpreting cerebrospinal fluid pleocytosis in HIV in the era of potent antiretroviral therapy. BMC Infect Dis 7: 37.

Marra CM, Zhao Y, Clifford DB, Letendre S, Evans S, Henry K, Ellis RJ, Rodriguez B, Coombs RW, Schifitto G, et al. 2009. Impact of combination antiretroviral therapy on 
cerebrospinal fluid HIV RNA and neurocognitive performance. AIDS 23: 1359-1366.

Martín-García J, Cocklin S, Chaiken IM, González-Scarano F. 2005. Interaction with CD4 and antibodies to CD4induced epitopes of the envelope gp120 from a microglia-adapted human immunodeficiency virus type 1 isolate. J Virol 79, 6703-6713.

Martín-García J, Cao W, Varela-Rohena A, Plassmeyer ML, González-Scarano F. 2006. HIV-1 tropism for the central nervous system: Brain-derived envelope glycoproteins with lower CD4-dependence and reduced sensitivity to a fusion inhibitor. Virology 346: 169-179.

Mellgren A, Price RW, Hagberg L, Rosengren L, Brew BJ, Gisslen M. 2007. Antiretroviral treatment reduces increased CSF neurofilament protein (NFL) in HIV-1 infection. Neurology 69: 1536-1541.

Meyerhoff DJ, MacKay S, Poole N, Dillon WP, Weiner MW, Fein G. 1994. N-Acetylaspartate reductions measured by $1 \mathrm{H}$ MRSI in cognitively impaired HIV-seropositive individuals. Magn Reson Imaging 12: 653-659.

Meyerhoff DJ, Bloomer C, Cardenas V, Norman D, Weiner MW, Fein G. 1999. Elevated subcortical choline metabolites in cognitively and clinically asymptomatic $\mathrm{HIV}^{+}$ patients. Neurology 52: 995-1003.

Navia BA, Cho ES, Petito CK, Price RW. 1986a. The AIDS dementia complex: II. Neuropathology. Ann Neurol 19: $525-535$.

Navia BA, Jordan BD, Price RW. 1986b. The AIDS dementia complex: I. Clinical features. Ann Neurol 19: 517-524.

O’Donnell LA, Agrawal A, Jordan-Sciutto KL, Dichter MA, Lynch DR, Kolson DL. 2006. Human immunodeficiency virus (HIV)-induced neurotoxicity: Roles for the NMDA receptor subtypes. J Neurosci 26: 981-990.

Perry H, Nicoll JAR, Holmes C. 2010. Microglia in neurodegenerative disease. Nat Rev Neurol 6: 193-201.

Peters PJ, Bhattacharya J, Hibbitts S, Dittmar MT, Simmons G, Bell J, Simmonds P, Clapham PR. 2004. Biological analysis of human immunodeficiency virus type $1 \mathrm{R} 5$ envelopes amplified from brain and lymph node tissues of AIDS patients with neuropathology reveals two distinct tropism phenotypes and identifies envelopes in the brain that confer an enhanced tropism and fusigenicity for macrophages. J Virol 78: 6915-6926.

Pilcher CD, Shugars DC, Fiscus SA, Miller WC, Menezes P, Giner J, Dean B, Robertson K, Hart CE, Lennox JL, et al. 2001. HIV in body fluids during primary HIV infection: Implications for pathogenesis, treatment and public health. Aids 15: 837-845.

Pillai SK, Pond SL, Liu Y, Good BM, Strain MC, Ellis RJ, Letendre S, Smith DM, Günthard HF, Grant I, et al. 2006. Genetic attributes of cerebrospinal fluid-derived HIV-1 env. Brain 129 (Pt 7): 1872-1883.

Pomara N, Crandall DT, Choi SJ, Johnson G, Lim KO. 2001. White matter abnormalities in HIV-1 infection: A diffusion tensor imaging study. Psychiatry Res 106: 15-24.

Price RW, Sidtis JJ, Brew BJ. 1991. AIDS dementia complex and HIV-1 infection: Aview from the clinic. Brain Pathol 1: $155-162$.

Pulliam L, Gascon R, Stubblebine M, McGuire D, McGrath MS. 1997. Unique monocyte subset in patients with AIDS dementia. Lancet 349: 692-695.
Reeve AB, Pearce NC, Patel K, Augustus KV, Novembre FJ. 2010. Neuropathogenic SIVsmmFGb genetic diversity and selection-induced tissue-specific compartmentalization during chronic infection and temporal evolution of viral genes in lymphoid tissues and regions of the central nervous system. AIDS Res Hum Retroviruses 26: 663-679.

Robertson K, Fiskus S, Kapoor C, Robertson W, Schneider G, Shepard R, Howe L, Silva S, Hall C. 1998. CSF, plasma viral load and HIV associated dementia. J Neurovirol 4: 90-94.

Robertson KR, Robertson WT, Ford S, Watson D, Fiscus S, Harp AG, Hall CD. 2004. Highly active antiretroviral therapy improves neurocognitive functioning. J Acquir Immune Defic Syndr 36: 562-566.

Robertson KR, Smurzynski M, Parsons TD, Wu K, Bosch RJ, Wu J, McArthur JC, Collier AC, Evans SR, Ellis RJ. 2007. The prevalence and incidence of neurocognitive impairment in the HAARTera. AIDS 21: 1915-1921.

Sacktor N, Nakasujja N, Skolasky RL, Rezapour M, Robertson K, Musisi S, Katabira E, Ronald A, Clifford DB, Laeyendecker O, et al. 2009. HIV subtype D is associated with dementia, compared with subtype A, in immunosuppressed individuals at risk of cognitive impairment in Kampala, Uganda. Clinical Infect Dis 49: 780-786.

Shau-Kwaun C, Tvrdik P, Peden E, Cho S, Wu S, Spangrude G, Capecchi MR. 2010. Hematopoietic origin of pathological grooming in Hoxb8 mutant mice. Cell 141: $775-785$.

Schacker T, Collier AC, Hughes J, Shea T, Corey L. 1996. Clinical and epidemiologic features of primary HIV infection. Ann Intern Med 125: 257-264.

Schnell G, Spudich S, Harrington P, Price RW, Swanstrom R. 2009. Compartmentalized HIV-1 originates from longlived cells in some subjects with HIV-1-associated dementia. PLoS Pathog 5: e1000395. doi: 10.1371/journal. ppat.1000395.

Schnell G, Price RW, Swanstrom R, Spudich S. 2010. Compartmentalization and clonal amplification of HIV-1 variants in the cerebrospinal fluid during primary infection. J Virol 84: 2395-2407.

Shieh JTC, Martín J, Baltuch G, Malim MH, GonzálezScarano F. 2000. Determinants of syncytia-formation in microglia by the human immunodeficiency virus type 1 (HIV-1): Role of the V1/V2 domains. J Virol 74: 693-701.

Sinclair E, Ronquillo R, Lollo N, Deeks SG, Hunt P, Yiannoutsos CT, Spudich S, Price RW. 2008. Antiretroviral treatment effect on immune activation reduces cerebrospinal fluid HIV-1 infection. JAcquir Immune Defic Syndr 47: 544-552.

Smit TK, Brew BJ, Tourtellotte W, Morgello S, Gelman BB, Saksena NK. 2004. Independent evolution of human immunodeficiency virus (HIV) drug resistance mutations in diverse areas of the brain in HIV-infected patients, with and without dementia, on antiretroviral treatment. J Virol 78: 10133-10148.

Smurzynski M, Wu K, Letendre S, Robertson K, Bosch RJ, Clifford DB, Evans S, Collier AC, Taylor M, Ellis R. 2011. Effects of central nervous system antiretroviral penetration on cognitive functioning in the ALLRT cohort. AIDS 25: 357-365. 
Soulas C, Donahue RE, Dunbar CE, Persons DA, Alvarez X, Williams KC. 2009. Genetically modified CD $34^{+}$hematopoietic stem cells contribute to turnover of brain perivascular macrophages in long-term repopulated primates. Am J Pathol 174: 1808-1817.

Soulas C, Conerly C, Kim W-K, Burdo TH, Alvarez X, Lackner AA, Williams KD. 2011. Recently infiltrating $\mathrm{MAC} 87^{+}$monocytes/macrophages. A third macrophage population involved in SIV and HIV encephalitic lesion formation. Am. J Pathol 178: 2121-2135.

Spudich S, Nilsson A, Lollo N, Liegler T, Petropoulos C, Deeks S, Paxinos E, Price R. 2005. Cerebrospinal fluid HIV infection and pleocytosis: Relation to systemic infection and antiretroviral treatment. BMC Infect Dis 5: 98.

Spudich S, Lollo N, Liegler T, Deeks SG, Price RW. 2006. Treatment benefit on cerebrospinal fluid HIV-1 levels in the setting of systemic virological suppression and failure. J Infect Dis 194: 1686-1696.

Spudich S, Gisslén M, Hagberg L, Lee E, Leigler T, Brew B, Fuchs D, Tambussi G, Cinque P, Hecht F, et al. 2011. Central nervous system immune activation characterizes primary HIV-1 infection even in subjects with minimal cerebrospinal fluid viral burden. J Infect Dis 204: 753760.

Sun B, Abadjian L, Rempel H, Calosing C, Rothlind J, Pulliam L. 2010. Peripheral biomarkers do not correlate with cognitive impairment in highly active antiretroviral therapy-treated subjects with human immunodeficiency virus type 1 infection. J Neurovirol 16: 115-124.

Thomas ER, Dunfee RL, Stanton J, Bogdan D, Taylor J, Kunstman K, Bell JE, Wolinsky SM, Gabuzda D. 2007a. Macrophage entry mediated by HIV Envs from brain and lymphoid tissues is determined by the capacity to use low CD4 levels and overall efficiency of fusion. Virology 360: 105-119.

Thomas ER, Dunfee RL, Stanton J, Bogdan D, Kunstman K, Wolinsky SM, Gabuzda D. 2007b. High frequency of defective vpu compared with tat and rev genes in brain from patients with HIV type 1-associated dementia. AIDS Res Hum Retroviruses 23: 575-580.

Thurnher MM, Castillo M, Stadler A, Rieger A, Schmid B, Sundgren PC. 2005. Diffusion-tensor MR imaging of the brain in human immunodeficiency virus-positive patients. AJNR Am J Neuroradiol 26: 2275-2281.
Pathogenesis and Management of Neuro-AIDS

Tozzi V, Balestra P, Salvatori MF, Vlassi C, Liuzzi G, Giancola ML, Giulianelli M, Narciso P, Antinori A. 2009. Changes in cognition during antiretroviral therapy: Comparison of 2 different ranking systems to measure antiretroviral drug efficacy on HIV-associated neurocognitive disorders. J Acquir Immune Defic Syndr 52: 56-63.

Valcour VGS, Cecilia M, Watters RM, Sacktor NC. 2004. Cognitive impairment in older HIV-1-seropositive individuals: Prevalence and potential mechanisms. AIDS 18 Suppl 1: S79-S86.

Valcour V, Paul R, Neuhaus J, Shikuma C. 2011. The effects of age and HIV on neuropsychological performance. J Int Neuropsychol Soc 17: 190-195.

van Marle G, Rourke SB, Zhang K, Silva C, Ethier J, Gill MJ Power C. 2002. HIV dementia patients exhibit reduced viral neutralization and increased envelope sequence diversity in blood and brain. AIDS 16: 1905-1914.

Wang Y, Zhang J, Gutman B, Chan TF, Becker JT, Aizenstein HJ, Lopez OL, Tamburo RJ, Toga AW, Thompson PM. 2009. Multivariate tensor-based morphometry on surfaces: Application to mapping ventricular abnormalities in HIV/AIDS. Neuroimage 49: 2141-2157.

Wiley CA, Schrier RD, Nelson JA, Lampert PW, Oldstone MB. 1986. Cellular localization of human immunodeficiency virus infection within the brains of acquired immune deficiency syndrome patients. Proc Natl Acad Sci 83: 7089-7093.

Wright EJ, Grund B, Robertson K, Brew BJ, Roediger M, Bain MP, Drummond F, Vjecha MJ, Hoy J, Miller C, et al. Cardiovascular risk factors associated with lower baseline cognitive performance in HIV-positive persons. Neurology 75: 864-873.

Xing HQ, Hayakawa H, Izumo K, Kubota R, Gelpi E, Budka H, Izumo S. 2009. In vivo expression of proinflammatory cytokines in HIV encephalitis: An analysis of 11 autopsy cases. Neuropathology 29: 433-442.

Yilmaz A, Stahle L, Hagberg L, Svennerholm B, Fuchs D, Gisslen M. 2004. Cerebrospinal fluid and plasma HIV-1 RNA levels and lopinavir concentrations following lopinavir/ritonavir regimen. Scand J Infect Dis 36: 823-828.

Yilmaz A, Price RW, Spudich S, Fuchs D, Hagberg L, Gisslen M. 2008. Persistent intrathecal immune activation in HIV-1-infected individuals on antiretroviral therapy. J Acquir Immune Defic Syndr 47: 168-173. 


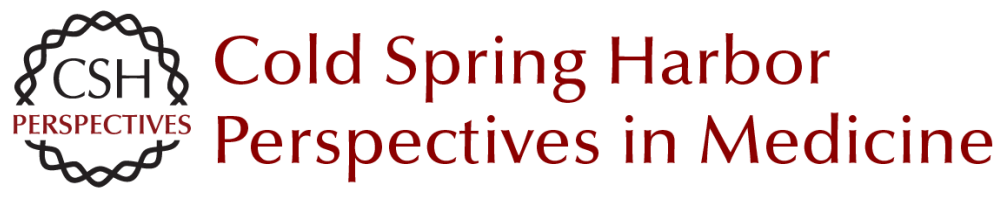

\title{
HIV-1-Related Central Nervous System Disease: Current Issues in Pathogenesis, Diagnosis, and Treatment
}

\author{
Serena Spudich and Francisco González-Scarano
}

Cold Spring Harb Perspect Med 2012; doi: 10.1101/cshperspect.a007120 originally published online February 28, 2012

\section{Subject Collection HIV}

HIV Pathogenesis: Dynamics and Genetics of

Viral Populations and Infected Cells John Coffin and Ronald Swanstrom

Human Immunodeficiency Virus Vaccine Trials Robert J. O'Connell, Jerome H. Kim, Lawrence Corey, et al.

HIV Transmission George M. Shaw and Eric Hunter

Novel Cell and Gene Therapies for HIV James $A$. Hoxie and Carl $H$. June

Behavioral and Biomedical Combination Strategies for HIV Prevention Linda-Gail Bekker, Chris Beyrer and Thomas C. Quinn

HIV-1 Assembly, Budding, and Maturation Wesley I. Sundquist and Hans-Georg Kräusslich

HIV-1 Assembly, Budding, and Maturation Wesley I. Sundquist and Hans-Georg Kräusslich

Lessons in Nonhuman Primate Models for AIDS Vaccine Research: From Minefields to Milestones Jeffrey D. Lifson and Nancy L. Haigwood
HIV-1 Pathogenesis: The Virus

Ronald Swanstrom and John Coffin

The T-Cell Response to HIV Bruce Walker and Andrew McMichael

HIV-1 Reverse Transcription Wei-Shau Hu and Stephen H. Hughes

HIV Pathogenesis: The Host A.A. Lackner, Michael M. Lederman and Benigno Rodriguez

HIV: Cell Binding and Entry Craig B. Wilen, John C. Tilton and Robert W. Doms

Innate Immune Control of HIV Mary Carrington and Galit Alter

HIV DNA Integration Robert Craigie and Frederic D. Bushman

HIV-1-Related Central Nervous System Disease: Current Issues in Pathogenesis, Diagnosis, and Treatment Serena Spudich and Francisco González-Scarano

For additional articles in this collection, see http://perspectivesinmedicine.cshlp.org/cgi/collection/ 